\title{
Government Support and R\&D Investment Effectiveness in Chinese SMEs: A Complex Relationship*
}

\author{
Claudio Petti \\ Department of Engineering for Innovation \\ University of Salento \\ clo Ed. A. Romano - Campus Ecotekne \\ Via per Monteroni SN \\ 73100 Lecce, Italy \\ claudio.petti@unisalento.it
}

\section{Lauretta Rubini}

Department of Economics and Management

University of Ferrara

Via Voltapaletto, I I

44I2I Ferrara, Italy

lauretta.rubini@unife.it

\author{
Silvia Podetti \\ Management and Health Laboratory \\ Institute of Management \\ Scuola Superiore Sant'Anna \\ Via San Zeno 2 \\ 56127 Pisa, Italy \\ and \\ Department of Statistics, Informatics and Applications (DiSIA) \\ University of Florence \\ Viale Morgagni 59 \\ 50134 Firenze, Italy \\ s.podetti@sssup.it
}

\begin{abstract}
This paper investigates the combined role of innovation support policies and firm's own innovative activities on the performance of Chinese small- and medium-sized enterprises (SMEs) in high-tech sectors. By distinguishing two components of innovative activities - research and development (R\&D) investments and embedded innovative capacity - the paper develops and tests an integrative moderated moderation model. The results suggest that in Chinese high-tech SMEs innovation-support policies positively moderate the relationship between R\&D investments and performance, but this positive effect diminishes when there are higher levels of embedded innovative capacity. These results highlight that the relationship between government innovation policies and a firm's own R\&D investments is not only reciprocal but also more complex than the one so far analyzed in the literature. The results show in particular that the effects of innovation-support policies on R\&D investments is not as neat as it seems, because of the internal balance within the firm between investment in R\&D and

* Part of the research leading to these results was supported by the financial contribution of the European Union under an FP7/ 2007-2013 Marie Curie International Research Staff Exchange Scheme under REA grant agreement n. 610350, Project E.N.T.I.C.E. - Explaining the Nature of Technological Innovation in Chinese Enterprises. We would also like to thank the referees for their valuable suggestions, which greatly helped us improve our analysis.
\end{abstract}


other sources of innovation. Therefore, although innovation support policies have been found to help Chinese SMEs in high-tech sectors benefit from their R\&D investments, these policies are particularly effective only when R\&D investments are significantly driving firms' innovative activities. This highlights the relevance of both government support and a firm's own efforts in the competitive modernization of Chinese SMEs.

\section{Introduction}

Innovation has been at the center of scholarly interest for several decades. It allows firms to maintain and strengthen their competitive advantage, it is one of the main determinants of economic progress and, more generally, it ultimately leads to an increase in social well-being. Fostering innovation is also among the main aims of policy agendas at all levels—local, regional, national and international—not only in advanced economies, but also in the emerging ones. There are numerous reasons cited in the literature to explain the policy attention given to innovation worldwide, including the need to foster research and development $(R \& D)$ projects with low returns for private investors but high social impacts (Edquist 2001), the necessity to solve market failures related, for example, to incomplete appropriability or knowledge spillovers (Arrow 1962; Woolthuis et al. 2005; Dodgson et al. 2011), and, more generally, the belief that innovation will have an impact on socioeconomic issues such as growth or the environment (Borrás 2003; Borrás and Edquist 2013).

In China, the most recent 2006-20 long-term plan for the development of science and technology, also known as SciTech Guideline, assigns a leading role to innovation and, in particular, to technology-led and domestic-based innovation. The aim is to support the transition of the Chinese economy towards a more sustainable growth model, based on an increase in high value-added production. The business sector is supposed to be the key driver of this transformation. This objective clearly emerges in the details of the SciTech Guideline, which features a full set of measures designed to support the creation of an innovation-friendly environment and deploys significant resources to do that. Among these measures are the promotion of domestic intellectual property and reinforcement of its protection; the introduction of fiscal incentives and a public procurement policy aimed at stimulating private investment in innovation; support to private risk capital investment in innovative firms; and the attraction and return of talent. The two subsequent five-year plans - the 11th (2006-10) and the 12th (2011-15) — have reinforced this approach and identified areas to be developed, priority projects, emerging technologies and, most of all, a set of specific objectives to be achieved in these fields. The 13th Five-Year Plan (2016-20) follows and reinforces the endeavors of previous plans. 
Nonetheless, the distinctive element of this policy is not so much the support to independent innovation per se, but rather the ultimate acknowledgment of the central role of the business sector within the national innovation system, previously assigned to government research institutes. Actually, while the SciTech Guideline was in the pipeline, the business subsector was already the most important contributor to national R\&D, in terms of both input and output (OECD 2008). Within the business sector, in particular, an important role is increasingly assigned to small- and medium-sized enterprises (SMEs), which are key players in the economic development of the country and represent the vast majority of Chinese firms (Di Tommaso, Rubini, and Barbieri 2012).

This growing importance of the private sector, however, does not seem to question the role that the state sector has played in China since ancient times. The relevance of the government in the Chinese innovation system remains one of its most characteristic elements, together with the peculiar scientific and industrial relationships system inherited from the period antecedent to the "reform and opening" policy (Di Tommaso, Rubini, and Barbieri 2012; Petti 2012; Rubini and Barbieri 2013). This framework, along with other factors such as the important position of state-owned enterprises in the Chinese innovative system and the "entrepreneurial role" played by the government in high-tech sectors (e.g., the high-speed railway system), raises curiosity about the extent to which government support still influences the innovation effectiveness of Chinese firms. Particularly interesting is the impact of government support on SMEs, which are known to have different innovative paths from larger firms (Acs and Audretsch 1988; Spithoven, Vanhaverbeke, and Roijakkers 2012) and which are important sources of employment, growth, and innovation, especially in high-tech sectors (see, among others, Colombo and Grilli 2007; Vivarelli 2007).

This study investigates the combined role of innovation support policies and firms' own innovative activities on the performance of Chinese SMEs active in high-tech sectors, distinguishing between the two main sources of innovation used in a small firm, namely, formal and informal R\&D. The paper designs a comprehensive moderated moderation model, which considers the moderating effect of innovation support policies along with its concurrent moderating effect on firm-embedded innovative capacity, on the relationship between R\&D investments and performance. The following sections review the relevant literature, develop the model, illustrate the empirical analysis performed, and discuss the obtained results.

\section{Firms' innovation activities, innovation-support policies, and performance: Literature review}

Investments in $R \& D$ are not the sole source of productivity gains and innovation. This is particularly true in the case of SMEs, for which several studies show no correlation 
between firm-level R\&D investments and growth (see, among others, Oakey, Rothwell, and Cooper 1988; Hall 1991). Indeed, even SMEs with low or no R\&D investments are able to achieve productivity gains. This means that they do so in a different way. In particular, some authors have identified "informal" sources of R\&D (in contrast to formal $R \& D$ investment separately indicated in the balance sheets), more often applied in SMEs than in large firms (Santarelli and Sterlacchini 1990; Ortega-Argilés, Vivarelli, and Voigt 2009; Rammer, Czarnitski, and Spielkamp 2009).

In some cases this informal R\&D is related to what we could call embedded innovative capacity (EIC) — that is, a set of investments in physical/overall capital that induce an endogenous innovation process of technology updating through the replacement of old machinery and equipment (see Santarelli and Sterlacchini 1990; Ortega et al. 2010). This leads, especially in low-tech sectors, to incremental (Santarelli and Sterlacchini 1990) or process innovation (Conte and Vivarelli 2005).

All of the previously mentioned studies, however, analyze the issue from either a size or sectoral perspective. This means that they are able to clearly explain the differences in terms of innovation inputs and the nature of innovation between large and mediumsized firms or between low- and high-tech firms, but they do not focus at the same time on similar firms within the same sector and, more specifically, on SMEs in high-tech sectors. Furthermore, none of them explicitly analyze what happens if formal and informal R\&D sources coexist.

This aspect is particularly important for its impact in terms of policy. What we know from previous work (Ortega-Argilés et al. 2010) is that these two R\&D sources require different funding and different supporting policies. Furthermore, since formal and informal R\&D often coexist within the firm, it becomes particularly difficult to discern which of the two (or, more relevantly, what interaction between the two) leads to a specific final output. It seems reasonable to assume that the two types of R\&D interact between themselves and with external funding (such as public supporting funds) in the achievement, for example, of productivity, profitability, or growth. The relationship between a firm's R\&D investment (mainly the formal one), innovation support policies, and overall performance has been only partially explored, however.

More specifically, much has been written on the relationship between R\&D investment and performance. Several available empirical analyses agree on the fact that investment in research has a positive effect both at the macro level (on variables such as growth, employment, and productivity [Barbieri, Iorio, and Lavadera 2010]) and at the micro level (on firm-level outcomes [see, e.g., Wakelin 2001; Sher and Yang 2005; Hosseini and Narayanan 2014]). High levels of R\&D investment are typically associated either with new technological breakthroughs in product development or with incremental innovation 
processes (Utterback and Abernathy 1975). Ortega-Argilés et al. (2010) focus on hightech firms, demonstrating not only that they tend to invest more in R\&D, but also that the investments result in higher productivity gains, reflecting a better capability to transform R\&D investments into improved innovation, particularly product innovation (Conte and Vivarelli 2005) and overall performance. At the firm level, Wakelin (2001), in a study based on a sample of UK firms, asserts that private firms' investment in R\&D has a positive influence on performance. Sher and Yang (2005) found a similar effect on profitability in Taiwanese electronic firms. Nevertheless, there are also studies showing more contradictory results. For example, Pantagakis, Terzakis, and Arvanitis (2012) investigate the relation between R\&D investment, performance, and market value. Although the impact of $R \& D$ on the market value is positive, this is not true for performance. Geroski's empirical work (1995) also shows a very weak relationship between R\&D spending and firms' performance, regardless of their size.

Some scholars have then studied the relationship between public policies supporting research and performance. This is mainly done indirectly, that is, by analyzing the relationship between public subsidies to research and private investments in R\&D (therefore implying a positive impact of private investment on performance), and seeing if there is a substitution or complementary effect between the two. As noted by Barbieri et al. (2010), the results of existing empirical analyses (mostly carried out using firm-level data) are inconsistent. The majority of studies seem to agree that public subsidies for research magnify the R\&D efforts of enterprises (see, among others, Adams 1990; Acs, Audretsch, and Feldman. 1991; Almus and Czarnitzki 2001). There are also studies highlighting the absence of effects of public subsidies on private investment in research (Lichtenberg 1987; Kaiser 2006), however. Some commentators even report a substitution effect between the two, with public subsidies used for investments in innovation that firms would have implemented anyway (Carmichael 1981; Toivanen and Niinien 1998). In other cases, the effect is different according to the size of the subsidy (Lööf and Hesmati 2005; Görg and Strobl 2007), to the methodology used (Cerulli and Potì 2012), or to the type of public support instrument adopted (David and Hall 2000; Barbieri et al. 2010).

Studies directly analyzing the relationship between policies supporting innovation and performance are far less abundant. Some studies identify the consequences for firms (e.g., Tidd and Brocklehurst 1999), whereas others examine the effects at a more macro level, with reference to the sector or territory (e.g., Piekkola 2007). Attempts to investigate $R \& D$, innovation-support policies, and performance at the same time are even scarcer. In general, these use a two-stage analysis that first studies the effects of innovation polices, mainly subsidies, on private investment in R\&D and then the corresponding impacts on innovative performance, measured in different ways. Czarnitzki and Hussinger (2004), for example, applied a two-step methodology to German firms and find that: (1) public support seems to accelerate private R\&D investment; and (2) by separating the purely 
financed part of total R\&D (that firms would have spent regardless of public subsidies) from the private R\&D investment stimulated by the subsidy, they show that both components have a positive impact on the patenting behavior of firms. Xu and Xu (2013) apply a multilevel analysis to a sample of 54 Chinese high tech industrial parks. Consistent with the former authors, $\mathrm{Xu}$ and $\mathrm{Xu}$ found a strong and causal effect on government taxation incentives on firms R\&D investment. They found a statistically insignificant relationship with innovation performance, however, unless a time lag is considered.

Although these attempts are valuable because they shed some light on the complex relationship between R\&D private investment, R\&D subsidies, and performance, none of them make any distinction between formal and informal R\&D and they all neglect to consider the possible interaction and moderation effects among the three variables. A variety of scenarios are possibly in this context:

(1) The positive impact found in the literature of government innovation-support policies on R\&D investment may magnify the positive effects of the latter on the firm's performance. This could happen if there are positive effects of the policies on the firm's absorptive capacity (Cohen and Levinthal 1989, 1990) through two possible channels: first, by facilitating the interpretation of technological and market signals or by generating such signals, thereby increasing firms' capabilities to better predict future technological advances and their commercial applications; and second, by easing the assimilation and exploitation of technological advances, thereby fuelling product, process, and organizational innovations (Cohen and Levinthal 1994; Zahra and George 2002).

(2) It is also possible that the relation between government policies and R\&D investments has the same inverted U-shaped form found in the relationship between government taxation incentives and R\&D expenditure ( $\mathrm{Xu}$ and $\mathrm{Xu}$ 2013) and between R\&D expenditure and profitability (Sher and Yang 2005). That is, just as there are threshold levels for R\&D expenditure, there may well be the same effect for policies, and these effects altogether may influence performance. For example, high levels of governmental support may boost R\&D investments, which will have positive effects but only until R\&D investments reach the efficient/optimal level. In fact, decreasing returns of R\&D activities have been found in the high-tech sectors (Conte and Vivarelli 2005). On the other hand, firms that invest in R\&D may benefit more from government policies supporting innovation. If it is true that government support amplifies the effects of R\&D investment on performance, it could also be the case that the level of R\&D investment influences the effectiveness of government support for firm performance.

(3) In some cases, R\&D funding is used for the acquisition of external technology (such as equipment or outsourcing) rather than for long-term technology development objectives. This has been shown to be particularly true for Chinese technology companies (Guan et al. 2006), and it could be more frequent in SMEs operating in contexts where 
there are difficulties in gathering enough funds to finance long-term expensive R\&D, as is, again, the case in China. Therefore, on one side public support for innovation may increase the effectiveness of R\&D investment, but on the other the previously mentioned preference for technology acquisition, ceteris paribus, and net of other sources of funds might diminish such effectiveness, diverting resources and energies from long-term, more significant innovations.

These are all reasons for devising and using integrated interaction models, which investigate the behavior of these variables in integration rather than in isolation or in a phased approach. One such attempt to use interaction models is the work of Czarnitzki and Lopes Bento (2011), who estimate the effects of European and national public grants on the performance of a sample of German firms, considering the effect of different grant combinations. This only provides a partial picture, however, which does not consider the role of private firms' investment nor does it directly investigate interaction effects, but only considers cumulative effects. Here, we adopt a comprehensive model that considers at the same time the combined effects of innovation-support policies, R\&D investments, and embedded innovative capacity. In other words, the literature has highlighted the fact that public subsidies have an effect on internal formal R\&D investments, which in turn have an impact on performance. In our model, these effects are analyzed simultaneously and take into account a broader range of innovative activities, drawing what seems to us a more realistic picture, especially for SMEs.

\section{Methods}

\section{I Data source, sampling methodology, and data selection}

The data for the analysis were selected from the data set of the Ninth National Private Enterprise Survey (NNPES). The survey was undertaken in 2010 by the United Front Work Department of the CPC Central Committee, the All-China Federation of Industry and Commerce, the State Administration for Industry and Commerce and the Chinese public (private) Economy Research Association. The access to the data set has been provided in the framework of the collaboration of one of the authors with the Research Centre for Chinese Family businesses at Sun Yat-Sen University.

The NNPES data set refers to 2009 and it includes data from 4,614 private SMEs, which involves between 0.1 to 0.2 percent of Chinese private enterprises ( $\mathrm{Lu}$ and Tao 2009; Lu, Tao, and Wang 2010) The survey covers all Chinese provinces and 19 out of the 20 sectors classified by the Chinese National Economic Industrial Classification, with the exclusion of "International Organizations." Data were collected by sending a questionnaire to the owner of such enterprises. The questionnaire included 39 questions covering many aspects of the entrepreneur and their family background, the firm's basic and financial 


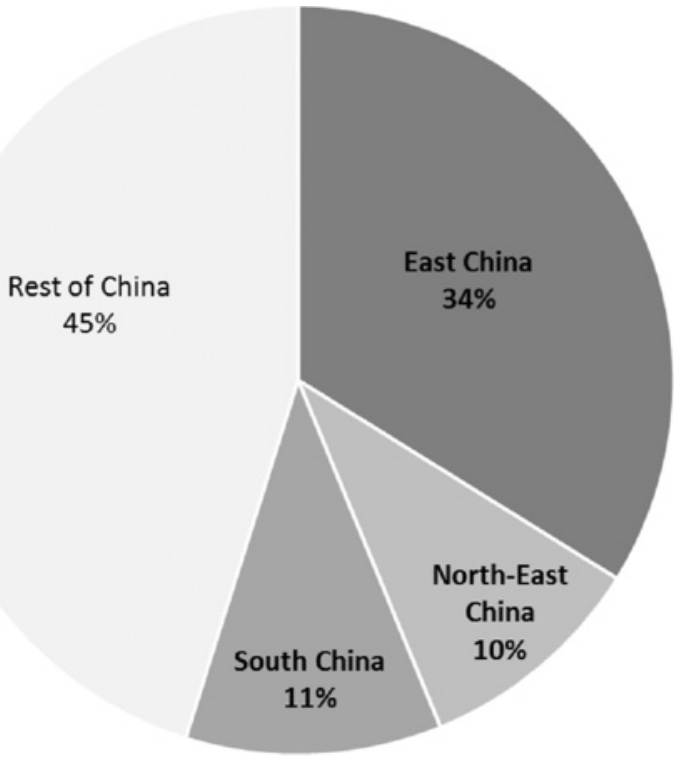

information (i.e., year of registration, typology, ownership, industry, number of employees, composition of capital and expenses breakdown), loans, recruitment and management, internationalization, and, particularly relevant for the present work, the evaluation of policy effects. In this last regard, covering all provinces, this data set generates enough variation in local institutional settings to make our analysis meaningful.

The NNPES used a multi-stage stratified random sampling method to achieve a balanced representation of private enterprises across all Chinese provinces and industrial sectors. The analysis carried out in this work is based on a sample selected ${ }^{1}$ from the NNPES data set covering all Chinese provinces made of 405 small and medium-sized private manufacturing enterprises operating in the fields of new materials, bio, clean and renewable energies, and aerospace, where there is most likely to be evidence of innovative activities. The majority of the considered firms (more than 80 percent) were small enterprises with fewer than 300 employees, with an average of 172 employees per company. The average age of the firms in the sample is about eight years, with the oldest registered in 1989 and the youngest registered in 2009. Figure 1 reports the geographical distribution of the sample analyzed with one-third of the enterprises in the subsample located in East China. The

1 To be more specific, only those enterprises that answered all the questions included in the NNPES questionnaire were considered. 
other noticeable concentrations are in the northeast and coastal regions of South China, with about 10 percent of the sample in each.

\subsection{Operationalization of variables and descriptive statistics}

The empirical analysis of this work was carried out by the operationalization of four variables: firm's performance (Perf_F), R\&D investment (RDinv), innovation support policies (Inno_pol), and embedded innovative capacity (EIC) as follows:

Dependent variable Firm's performance (Perf_F) was measured using a firm's 'profits in 2009' reduced by the amount of subsidies and tax reliefs in the same year. This is because in the Chinese context, some inputs and industries are heavily and differently subsidized and incentivized, therefore it is necessary to depurate profits from these figures, when available. A profit-based measure of performance was eventually preferred to a revenue/turnover-based one, often used for this purpose in the Chinese context, since this latter is more used to measure size rather than performance (see, among others, Hansen and Wernerfelt 1989).

Independent variables R\&D investments (RDinv) were measured as a firm's 'R\&D expenditure in 2009' on the 'total number of full-time employees' in the same year. The use of this ratio instead of, for example, R\&D expenditure on sales, avoided the issue of any possible artificial relationship with firm's performance, which nonetheless may be correlated to some extent with a firm's sales. In addition, though R\&D expenses take time to produce results, a time lag between $R \& D$ investments and performance measure was not considered in this study. This could have been an option should the used data set have previous years' data. We think this is not a severe limitation, however, because of the diffused incremental nature of innovation in Chinese firms' settings, from traditional manufacturing to high-tech, which makes the time-to-market for new products (the tangible, intermediate outcomes of R\&D expenses as related to their transformation in performance) often shorter than one year. Indeed, according to a specific analysis carried out on a sample of 113 Guangdong technology enterprises (cited in Petti 2014), the average time-to-market was 6.5 months, with just 10 percent of the companies having a time-to-market equal to or longer than one year. Furthermore, the nature of R\&D expenses of Chinese firms tends to be directed towards key equipment and technology acquisitions to increase their productivity and enhance their economic performance rather than to the development of new products and technologies (Guan et al. 2006). Therefore, the short-term nature of R\&D expenses by Chinese firms on average makes it reasonable to assume that these expenses come to be realized in the same year they are sustained.

Innovation support policies (Inno_pol) were measured using the amount of government technology-related financial support received in 2009. For the reasons given earlier, a time 
Table 1. Summary statistics of the variables Perf_F (firm's performance), RDinv (R\&D investments), Inno_Pol (innovation-support policies), and EIC (embedded innovative capacity)

\begin{tabular}{|c|c|c|c|c|c|}
\hline & $\mathbf{N}$ & Minimum & Maximum & Mean & Std. Deviation \\
\hline \multicolumn{6}{|l|}{ Firm's Performance (Perf_F) } \\
\hline $\begin{array}{l}\text { Profits - subsidies \& tax reliefs in } 2009 \text { (10,000 RMB) } \\
\text { RED Investments (RDinv) }\end{array}$ & 405 & $-3,463$ & 23,421 & 531.015 & $2,083.95$ \\
\hline R\&D expenditure in 2009 (10,000 RMB) & 405 & 0.00 & 8,520 & 152.99 & 678.74 \\
\hline Innovation Support Policies (Inno_pol) & 405 & 0.00 & 1,739 & 31.05 & 137,26 \\
\hline \multicolumn{6}{|l|}{ Embedded Innovative Capacity (EIC) } \\
\hline Intellectual property in capital (\%) & 405 & 0.000 & 70.00 & 3.57 & 9.52 \\
\hline Non-protected owned technology in capital (\%) & 405 & 0.000 & 30.00 & 1.32 & 4.06 \\
\hline Total number of full-time employees in 2009 & 405 & 2 & 1,980 & 172 & 270 \\
\hline Company age (years) & 405 & 0 & 20.00 & 7.98 & 4.38 \\
\hline Valid N & 405 & & & & \\
\hline
\end{tabular}

Source: Authors' calculations.

lag between innovation support polices and performance measure is not introduced in the model.

The firm's embedded innovation capacity (EIC) was measured as the sum of "percent intellectual property" and "percent of non-protected owned technology" in a firm's capital composition. This is in line with the definition of informal R\&D provided by Santarelli and Sterlacchini (1990), who include in this category patents, intermediate and capital goods, and design- and industrialization-related investments.

Finally, the items "total number of full-time employees in 2009," "age of company since the year of registration," and "province ZIP codes" were introduced in the model as covariates to control respectively for size, age, and localization of firms. No industry control was necessary because all sample firms belong to a specific subgroup within the same industry (i.e., emerging or advanced manufacturing).

At first, the descriptive analysis of the independent variable Perf_F shows that the overall proportion (mean) of profits depurated from the amount of subsidies and tax reliefs in 2009 of the considered firms was about RMB 5.3 million. With reference to the dependent variable RDinv, on average in 2009 firms invested in R\&D approximately RMB 1.5 million, and Inno_pol amounted on average to RMB 310 thousand. The variable EIC shows that intellectual property and non-protected owned technology accounted on average for 3.6 percent and 1.3 percent of firm-level capital respectively (Table 1).

\section{Econometric model and results}

\section{I Model}

The statistical model fitted in this analysis is derived from the moderation modeling framework (Baron and Kenny 1986). In particular, what we use is a more recent development of the moderation techniques suggested by Preacher, Rucker, and Hayes (2007) 

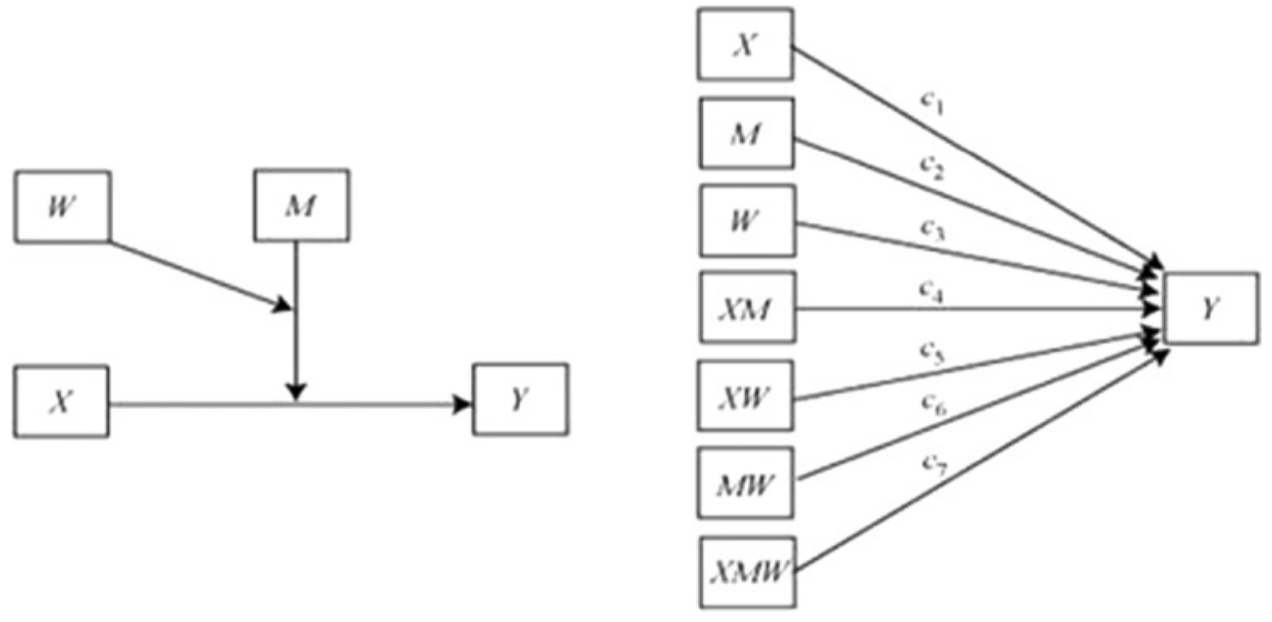

Source: Hayes 2012.

and other authors (Aiken and West 1991; Jaccard and Turrisi 2003). This model allows us to test the magnitude effect of an independent variable on a certain dependent variable, an effect that depends on the presence of a third variable or set of variables, called moderator/s. When some moderator variables are used in interaction with one or more independent variables, the result is an increase in the robustness of the fitted relationship. In fact, the analysis of the conditional effects due to one or more moderators of $X$ on $Y$ allows explaining "when" (i.e., on the basis of what individual differences or under the presence of what conditions) some kind of effect of $X$ occurs on $Y$ (Stolzenberg 1980; Tate 1998).

In particular, we estimated a moderated moderation model, also known as a three-way interaction model. The conceptual model of the relation we tested is shown on the lefthand side of Figure 2. As explained by Hayes (2012), X is shown to exert a causal influence on $Y$, reflected by the unidirectional arrow pointing from $X$ to $Y$. This effect is proposed to be influenced or moderated by two other variables, $M$ and $W$, which exert a multiplicative effect in the relation between $X$ and $Y$. The statistical model can also be represented visually in the form of a path diagram, as shown on the right-hand side of Figure 2, in which the multiplicative effects exerted by $M$ and $W$ (and those sought in this study) are clarified.

In particular, this diagram summarizes a linear equation in which $Y$ is estimated as a weighted function of $X, M$, and $W$, and, most typically, the product of $X$ and $M$ 
$(X M)$, the product of $X$ and $W(X W)$, and the product of $X, M$, and $W(X M W)$, as in equation (1).

$$
\mathrm{Y}=i+c_{1} X+c_{2} M+c_{3} W+c_{4} X M+c_{5} X W+c_{6} M W+c_{7} X M W+e_{y}
$$

Three-way interaction, or moderated moderation, is present if the coefficient $\left(c_{7}\right)$ of the multiplicative effect of $M$ and $W$ on $X$ is statistically different from zero (among others, Aiken and West 1991; Jaccard and Turrisi 2003).

Our model posits an interactive effect of R\&D investment and innovation support policies on a firm's performance, as well as an interactive effect produced by the firm's embedded innovative capacity on the former interaction. According to our research question, this model examines the conditional nature of the interaction between R\&D investment $(X)$ and innovation-support policy $(M)$, as moderated by a firm's embedded innovative capacity $(W)$. Formally, the derived moderated moderation model is therefore the following:

$$
\begin{aligned}
& \text { Perf _F }=i+c_{1} R \text { Dinv }+c_{2} \text { Inno_pol }+c_{3} E I C+c_{5} R \text { Dinv }^{*} E I C+c_{6} I_{n n o} \text { pol }^{*} E I C \\
& +\left(c_{4}+c_{7} E I C\right)^{*} R \& \operatorname{Dinv}^{*} \text { Inno } p \text { pol }+e_{y},
\end{aligned}
$$

where the nature of the conditional effect of R\&D investment on a firm's performance is represented by the values and statistical significance of moderators coefficients $c_{4}$ and $c_{7}$ indicated in the reformulated equation

$$
\mathrm{Y}=i+c_{1} X+c_{2} M+c_{3} W+c_{5} X W+c_{6} M W+\left(c_{4}+c_{7} W\right) X M+e_{y}
$$

The estimate of the conditional effects of the two moderators on $X$ is made using the nonparametric method of bootstrapping, which allows the application of inferential tests on a population avoiding assumptions of a normal sampling distribution (Hayes 2012). The selected sample of firms considered here represents a pseudo-population of the total population of firms from which the sample is drawn. Hence, the sampling distribution of the statistical test is estimated based on a multiple re-sampling of our data set and the estimated standard error represents the standard deviation of the sampling distribution generated by the bootstrap sample. Because a no-symmetry assumption is made about the sampling distribution, the asymmetry of the resulting confidence intervals is justified.

Inference has been made by selecting the values of the second moderator, namely, innovation activities $(W)$, and testing whether the conditional interaction between R\&D investment $(X)$ and innovation support polices $(M)$ is statistically different from zero at those values. 
Table 2. Synthesis of results

\begin{tabular}{lrr}
\hline & Coeff. & $p$ \\
\hline$c_{1}$ & & \\
RDinv & 275.0202 & .0000 \\
$c_{2}$ & & \\
$\begin{array}{l}\text { Inno_pol } \\
c_{3}\end{array}$ & -0.0547 & 0.9345 \\
ETC & -0.4326 & 0.9543 \\
$c_{4}$ & & \\
int_1: RDinv*Inno_pol & 2.1329 & 0.0000 \\
$c_{5}$ & & \\
int_2: RDinv*EIC & -4.5506 & 0.0002 \\
$c_{6}$ & & \\
Int_3: Inno_pol*EIC & -0.0342 & 0.6332 \\
$c_{7}$ & & \\
Int_4: REDinv*Inno_pol*EIC & -0.0417 & 0.0003 \\
Size & 2.0986 & 0.0000 \\
Age & -10.3135 & 0.5752 \\
Province & -18.4798 & 0.2732 \\
\hline
\end{tabular}

Source: Authors' calculations.

\subsection{Results}

The analyzed sample far exceeded the minimum sample size requirements reported in the literature for the specific analysis at hand, which according to Stevens' $(1996,72)$ guidelines for multiple regression should include between 90 (at least 15 cases per predictor) and 120 cases (considering each sub-item of the moderators as a predictor).

The main results of the analysis applied to the selected sample of firms are shown in Table 2. In the absence of interactions between the independent variable (RDinv) and the moderators (Inno_pol and EIC) the coefficient $c_{1}$ of R\&D expenditure is positive (275.02) and statistically significant in explaining variations in the level of a firm's performance (Perf_F). On the other hand, the coefficient $c_{2}$ of the moderator variable Inno_pol and the coefficient $c_{3}$ of the moderator variable EIC are not statistically significant. When interactions are introduced into the model, the value of the coefficient $c_{4}$ of the product between RDinv and the moderator Inno_pol is positive $(2,1329)$ and the value of the coefficient $c_{7}$ of the product between RDexp, Inno_pol, and EIC is negative $(-0.0417)$. Both are statistically significant.

Of the other interactions, coefficients $c_{5}$ and ${ }_{C 6}$, only the one between $R \mathcal{E} D i n v$ and EIC was statistically significant with a value of -4.5506 , whereas the interaction between the two moderators $\left(c_{6}\right)$ turned out to be not statistically significant. Concerning the control variables (i.e., firm size, age and localization), only size turned out to be statistically significant.

As shown in Table 3, a look at the values of the proportion of the total variance of a firm's performance due only to the moderators reveals that the introduction of the threeway interaction between R\&D investments and the two moderators improves the fit of 
Table 3. Model $\mathbf{R}^{2}$ increase due to the threeway interaction

\begin{tabular}{llll}
\hline & $\mathbf{R}^{2}$ & $\mathbf{R}^{2}$ change & $p$ \\
\hline Model & 0.4349 & & 0.0000 \\
int_4: RDinv*Inno_pol*EIC & & 0.0191 & 0.0000 \\
\hline Source: Authors' calculations. & & &
\end{tabular}

\begin{tabular}{|c|c|c|}
\hline$E I C(W)$ & Effect & $p$ \\
\hline-4.8921 & 2.337 & 0.0000 \\
\hline-1.3921 & 2.191 & 0.0000 \\
\hline 2.1079 & 2.045 & 0.0000 \\
\hline 5.6079 & 1.899 & 0.0000 \\
\hline 9.1079 & 1.754 & 0.0000 \\
\hline 12.6079 & 1.608 & 0.0000 \\
\hline 16.1079 & 1.462 & 0.0000 \\
\hline 19.6079 & 1.316 & 0.0000 \\
\hline 23.1079 & 1.170 & 0.0001 \\
\hline 26.6079 & 1.025 & 0.0015 \\
\hline 30.1079 & 0.879 & 0.0132 \\
\hline 33.1620 & 0.752 & 0.0500 \\
\hline 33.6079 & 0.733 & 0.0587 \\
\hline 37.1079 & 0.587 & 0.1642 \\
\hline 40.6079 & 0.441 & 0.3346 \\
\hline 44.1079 & 0.296 & 0.5492 \\
\hline 47.6079 & 0.150 & 0.7775 \\
\hline 51.1079 & 0.004 & 0.9943 \\
\hline 54.6079 & -0.142 & 0.8147 \\
\hline 58.1079 & -0.288 & 0.6547 \\
\hline 61.6079 & -0.433 & 0.5246 \\
\hline 65.1079 & -0.579 & 0.4209 \\
\hline
\end{tabular}

Source: Authors' calculations.

the model. Looking at the $\mathrm{R}^{2}$ value, this interaction captures about 2 percent of a firm's performance variance.

Finally, an interesting insight came with reference to the nature of the conditional effects of R\&D investment moderators on a firm's performance (Preacher, Rucker, and Hayes 2007). The analysis demonstrates that, although the total conditional effect due to the moderation of innovation support policies on a firm's performance is positive, this effect decreases in combination with increasing values of the moderator embedded innovative capacity. In more detail, as shown in Table 4, inference is undertaken by using the Johnson-Neyman technique (see, e.g., Bauer and Currant 2005; Hayes and Matthes 2009), which marks the "regions of significance" of the effects of the interaction between the dependent variable $\left(R D_{i n v}\right)$ and the moderator (Inno_Pol) along the continuum of the other moderator (EIC). More specifically, the region of significance in our case is demarcated by the EIC value 33.1620. Analysing the effects of Inno_Pol moderation under this 
Figure 3. Innovation-support policies and innovation activities moderated moderation effects

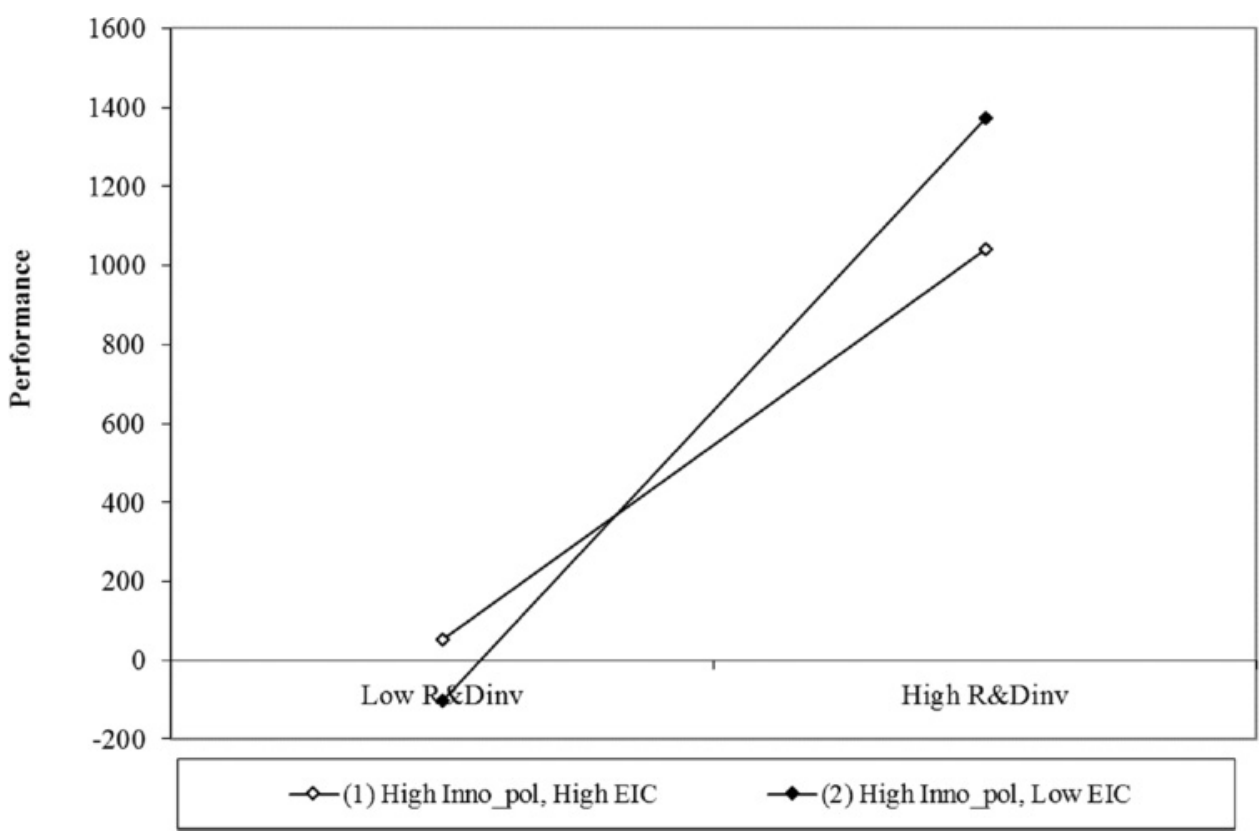

Source: Authors' calculations

value (second column), it can be seen that it diminishes with the increase of the embedded innovative capacity (first column) from 2.3367 at an EIC value of -4.8921 to 0.7516 at EIC value of 33.1620 .

The interaction effects, however, are beneficial only for those firms that present higher R\&D investments, as shown by the three-way interaction in Figure 3.

In synthesis, the data reveal that for those SMEs that are engaged in $R \& D$, innovation support policies are beneficial to the extent to which these firms' efforts are prominently focused on R\&D, because increases in the embedded innovative capacity lessen the conditional (beneficial) effects of policies in transforming R\&D investments into a firm's performance. That is, the relationships between R\&D investments, innovation support policies and performance in Chinese high-tech SMEs are moderated by informal R\&D activities in a way that the effects of innovation support polices are more positive for those firms with lower embedded innovative capacity than for those with higher embedded innovative capacity. 


\section{Discussion}

The specific technique used in this study simultaneously measures the combined effects of public support and the main modes of innovation carried out within a firm on the performance of Chinese SMEs active in high-tech sectors. Thus, it allows taking a step further concerning existing multi-stage analyses or indirect measurement approaches, by using an integrative model that also takes into account the interactions among the factors analyzed.

Findings extend to the Chinese context some of the results reached by the international literature, providing evidence that innovation-support policies positively moderate the relationship between R\&D investments and performance in Chinese SMEs active in hightech sectors. At the same time these findings enrich the existing literature by showing that when measures of a firm's different modes of innovation are considered, this relationship is not so straightforward, as there is a kind of trade-off between them that affects the effectiveness of innovation-support policies.

More specifically, these results show that innovation-support policies produce their beneficial effects particularly when the embedded innovative capacity of Chinese SMEs is low or, alternatively, that when there are higher levels of embedded innovative capacity, R\&D-related subsidies lose in effectiveness, at least in terms of their capacity to transform R\&D investments into actual performance. This may happen because, as hypothesized, it is more likely that R\&D subsidies are used for less systematic, productive and long-term forms of R\&D. Those are the kind of activities argued in literature to be less fruitful in generating productive gains and ultimately better performance and competitiveness (see Ortega-Argilés et al. 2010). Therefore, the level of R\&D investment and the attention of the firm towards it make the difference in the capabilities of the firms to benefit from the public hand.

As a first corollary, not all the public support to innovation is money well spent. It has to be directed to companies capable and willing to also use their own R\&D investments to engage in more significant innovation, in order to ultimately allow the firm to achieve enhanced performances.

As a second corollary, government support surely influences innovation effectiveness in China, and in Chinese SMEs in particular. Nevertheless, the government effort to support innovation, no matter how significant, may not be sufficient if the firms themselves do not complement it. Actually, our data show that the government subsidies lose effectiveness especially for those firms that, although investing in R\&D, also show high levels of embedded innovative capacity. This may be ascribed to the proclivity of Chinese firms to direct their R\&D expenses to outsourcing and acquisition of key equipment 
and technologies rather than focusing on internal technology development (see Guan et al. 2006).

Therefore, innovation effectiveness of Chinese firms appears to be based upon a complementary relationship between public support (which still exerts a significant influence) and a firm's initiative, which produces different effects depending on the inner balance within the firm's own innovation activities. In fact, the undertaken analysis also shows that innovation support policies do not produce any significant effect on performance unless they are combined with a firm's own R\&D investments.

The evidence of a negative and statistically significant interaction between R\&D investment and embedded innovation capacity-in other words, between formal and informal R\&D (see Table 2)—seems to support the idea of a competing relationship between the two and of a different performance in relation to policy support. In particular, informal $R \& D$ shows a lower effectiveness. Because of the used measure, however, it is not possible to exclude the existence of other reasons that may have negatively affected the performance. For example, some firms may own part of these assets for purposes not directly linked with any form of innovation (in this regard see Haroff 2011). This might therefore generate managing costs that offset the positive impact of such assets on firm's results, possibly ending in the negative sign of this variable in the obtained results.

In synthesis, our findings show that innovation in Chinese firms involves a mix of government support and firms' own efforts (Di Tommaso, Barbieri, and Huang 2010). In particular, to paraphrase Cohen and Levinthal (1994), it appears that government favors the prepared firms. If the firm's efforts in formal and long-term R\&D investments are large and more focused, then the effects of the government's influence on the firm's results will also be higher.

Some could argue that there is also a hidden and even distortive effect of state intervention on Chinese SMEs' innovative activity. For example, recent provincial programs to favor the increase in domestic patenting, especially by Chinese firms (Di Tommaso, Rubini, and Barbieri 2012; Li 2012), could have led to an "artificial" push in innovative activity of firms driven by non-long-term R\&D considerations. Although our analysis shows that acquired intellectual property (that is, part of the embedded innovative capacity) may be detrimental to the relationship between R\&D and policy support, we cannot know how much of the remaining R\&D investment is significant (i.e., oriented towards inventions rather than utility models and designs). In other words, this could be an (at least partial) effect of such policies that this study cannot measure. This would lead the discussion further towards the nature of the developmental state in China or even of its entrepreneurial role. We have already highlighted the strong government presence as one of the distinctive key features of the Chinese innovation system. Nevertheless, there are a number of 
reasons that, in our opinion, prove the relevant role played by the innovative activities of firms, whether or not they are further facilitated by other policies, with specific reference to the role of incentives to patents mentioned above. These include, first, the statistically insignificant effect of the innovation-support policies alone on performance; second, the lessening of these effects when firms' innovation efforts are limited; and finally, the fact that these policies produce their beneficial effect only for those firms that present higher levels of R\&D investments.

From another perspective, we could think that the nonsignificant impact of innovation support policies alone on performance could be the evidence of the existence of a recursive relationship between the two variables, namely, that performance influences support policy's effectiveness. In particular, it could be argued that the lack of satisfactory performance may prevent firms from benefittin from policy support. In fact, the distribution of profits shows a concentration towards lower values. It is therefore possible that firms with better performance have higher or easier access to public resources because their higher performance can give them the legitimacy and resources needed to obtain such a support. Suffice it to think that programs such as Innofund not only require specific minimum levels of investment in R\&D, but also a high innovative content in the presented projects, which only firms with a certain availability of resources can afford. This is therefore still an open question that could be the focus of further investigation in the future.

\section{Policy implications}

The wide availability of studies on the impact of innovation on industrial performances summarized in Section 2 indicates the relevance that the issue plays at the academic level. Nonetheless, this relevance is also reflected on the policymaking circuit. The support to technology upgrading of firms has been in the recent years one of the most popular policies implemented not only by many national governments, but even at a supranational level. The EC, for example, has been investing for years in a variety of different projects in order to favor the increase in the technological capacity and innovative potential of firms.

The Chinese government has also shown the same interest, and we can surely say that this is not a recent trend for the country. Since the start of the opening policy, at the end of the 1970s, policymakers have bet on the attraction of high-tech foreign firms on the mainland, in order to favor the technological spillover to local firms. In more recent years, great emphasis is being put on the development of a domestic innovative capacity, to be used as the key strategic tool to enter foreign markets, in line with the so-called "go abroad" strategy (Di Tommaso et al. 2012). Technology upgrading is the first key word of the leading planning documents both at national and at provincial and local level all over the country. 
To implement specific technology supporting policies is not synonymous with success per se, however. Analyses of the impact of such policies are needed in order to understand their actual effect on industry and on growth and to plan subsequent new actions. The support to high-technology firms could have a positive impact in terms of overall growth or unemployment reduction (Sjöholm and Lundin 2010; Zhao 2010), even if with different degrees of response rates (Fu, Xiong, and Chesbrough 2014). The efficacy of a technologysupporting policy depends not only on the magnitude of the intervention, but also on the conditions of the environment on which the policy acts.

The analysis carried out in the present work allows us to take into account the interaction between the policy intervention and the two main sources of firms' internal innovation at the same time, and to draw some important implications in terms of policymaking. The first implication is that the main need is not to vary the "quantity" of policy provided, but rather to a re-orient the state intervention. According to our results, it seems useful to divert state intervention from firms with a higher focus on technological acquisition and informal R\&D, for which such intervention is not effective and could even be harmful for the further development of their innovation capabilities, towards recipients where they can be more effective. This may produce further beneficial effects, because it may free resources to sustain cascading stages of development in which the "policy push" is increasingly targeted while overall industry innovation capabilities (and hopefully performance) intensify, generating multiplying effects coming from an increase in the numerator, a decrease in the denominator, or both.

In line with Ortega-Argilés et al. (2010), our findings support a targeted approach to innovation policy both in the distribution of subsidies and in the design of fiscal incentives, specifically, targeting R\&D investments. Our analysis also focused only on high-tech sectors, differentiating between firms following an R\&D-driven innovation mode and firms following an informal R\&D-driven innovation mode. Nonetheless, grounding on the passionate pages by von Mises (1949) about the distortive and perversive effects of discriminative government interventions, one could argue that such a specific policy approach could lead to severe distortions. Nevertheless, the high-tech sector and the innovative SMEs seem to have been an exception, enjoying sectoral selection and specific supportive policies as in von Mises' EU roundabouts.

Therefore, there seems to be both theoretical and empirical legitimating toward the use of targeted innovation support policies, at least within the high-tech sectors, if the objective is to make public spending more effective and productive. Provided, of course, that all the institutional and policy countermeasures are taken in order not to incur the well-known problem of government failure (rent seeking, regulator capturing, and, more in general, privilege-led and opportunistic behaviors). 
Other kinds of problems may also arise when such selective policies are not well targeted. Let us take as an example the latest version of the Chinese government procurement lists, where foreign brands like Cisco, Apple, Intel, and McAfee disappeared in favor of domestic suppliers for public administration IT. In the short run, these preferential policies could produce positive effects on firms that need to catch up, but not on the ones already showing good performance in innovation, which might have reached such performances anyway. In the long term, however, the overall effects could be double-edged and negatively affect both types of companies. Such a policy may in fact inhibit further innovative efforts of the most capable firms or force them to face similar retaliation policies in the international markets where they mostly operate. At the same time, the lagging-behind group of firms could be induced, thanks to the protection granted by the policy, to focus more than they should on technological acquisition and informal R\&D rather than developing more significant innovation capabilities. Therefore, if the negative relationship found in our work holds true, indiscriminate preferential policies might hamper the longterm prospects of both kinds of companies and make them fall in the lagging-behind, catching-up, and lagging-behind-again trap that has hampered Chinese innovation efforts since the beginning, generating and destroying waves of "policy push" measures.

Nonetheless, the presence of a positive impact of innovation policies testifies to the important role still played by the Chinese government in guiding and facilitating the steady growth of its productive system. This suggests that government intervention in the economy is still relevant, but it will be so only to the extent to which policymakers' decisions would be informed and grounded on appropriate data. This is especially true for the choice of policy targets, for which the availability of correct information should not be taken for granted.

Therefore, for all these reasons, we do not and cannot suggest a generalized disengagement of government innovation policies, but rather we believe that it is necessary to verify their applicability conditions not only at their design stage, but-borrowing an engineering metaphor-all over their lifecycle. We refer in particular to the choice of the target, the implementation timing, the testing, and the tuning of the results in order to avoid the trade-off between (short-term) benefits and (longer-term) distortive effects. A confirmation in this sense, but not the only one after the huge anti-crisis stimulus package, is the photovoltaic industry, where the echoes of the recent Wuxi Suntech Power Co. bankruptcy and re-organization raised doubts, within the local government itself, about the role of the strong support received by the company.

Therefore, if our preliminary data pass the test of further studies and proofs, a substantial review of indiscriminate and/or "policy push" approaches is needed, evaluating their effectiveness and, possibly, modifying them to fit the intended objectives and to try to avoid the unintended, but foreseeable, effects. This should be done using, if not a 
"scientific policy" approach, at least a good dose of common sense and of lessons coming from past experience.

In this framework, it seems reasonable to assume the existence of a layer of Chinese middle-sized private firms focused on $R \& D$, for which an injection of public resources could allow them to undertake an effective technological upgrading process and eventually to become important players even at the international level. According to our findings, these companies should become the target of ad hoc designed and time-limited "policy pull" measures, based on their specific innovation mode and pattern, which could have the highest impacts in making their own R\&D efforts effective and the government support worth the effort.

\section{Conclusions and future research}

This work demonstrates the existence of a complex relationship between innovation support policies and R\&D activity in the context of Chinese SMEs operating in high-tech sectors. More specifically, using a moderated moderation modeling framework, and stateof-the-art analysis techniques, it shows that this relationship depends on the innovation mode followed by the company, and that the impact of public innovation policies is reduced when the levels of informal R\&D within the firm are high.

These results are potentially interesting for both theory and practice. Under a theoretical perspective, these findings offer further support to complementary views of state support and business efforts in the specific Chinese context. More interestingly, for the broader implications transcending the Chinese context, this paper provides a comprehensive and direct analysis of variables otherwise studied separately and indirectly.

From a practitioner perspective, it provides specific indications to both Chinese policymakers and entrepreneurs about how to orient their policies and strategies to obtain the most from their respective research-related investments. The contributions of this work are broader, however, since it stimulates reflection on the appropriate extent of government support, its targeting, intensity, timing, and duration. In doing this, it definitely provides a contribution to the general debate on the need for an industrial policy (Di Tommaso and Schweitzer 2013).

Nonetheless, this work-far for being conclusive-represents only the first step of a research path that in the future may develop in different directions.

First of all, it would be interesting to test the model using different measures of performance or controlling for evolutions over time. Second, some aspects require further study, because they do not seem to be significant in the present analysis even if previous 
contributions available in the literature have underlined their relevance. One of these is certainly the absence of territorial differences in the behavior of firms. This result seems to be inconsistent with previous analyses (Di Tommaso and Rubini 2005; Barbieri, Di Tommaso, and Rubini 2009; Di Tommaso, Rubini, and Barbieri 2012), which show the existence of strong differences at the territorial level regarding the industrial development process. An explication could be the fact that the present work deals with local implementations of state policies. Further in-depth studies can be carried out by enlarging the sample to include a wider variety of sectors and to investigate whether there are differences, for example, between the manufacturing and the service sectors or with other sectors, as well as the possibility of taking into account a time lag between independent variables and paper for the Chinese state-owned enterprises. Not only has this typology of firms been profoundly reformed in these last few years (Di Tommaso, Rubini, and Barbieri 2012), but they are also in many cases the main recipients of public funding, even if it does not seem to have a particular impact on their innovative capacity. Additionally, the analysis could be deepened by carrying out comparative studies with other countries. This would allow us to investigate the extent to which the results obtained in this study can be generalized and extended to other realities.

Finally, yet importantly, the identification of conditions of policy applicability and thresholds on which most of the implications discussed in this work are based represents an overarching research challenge in itself, therefore worth pursuing for both its theoretical and practical applications.

\section{References}

Acs, Zoltan J., and David B. Audretsch. 1988. Innovation in large and small firms: An empirical analysis. The American Economic Review 78(4): 678-690.

Acs, Zoltan J., David B. Audretsch, and Maryann P. Feldman. 1991. Real Effects of Academic Research: Comment. American Economic Review 82(1):363-367.

Adams, James D. 1990. Fundamental Stocks of Knowledge and Productivity Growth. Journal of Political Economy 98(4):673-702.

Aiken, Leona S., and Stephen G. West. 1991. Multiple Regression: Testing and Interpreting Interactions. Thousand Oaks, CA: Sage.

Almus, Matthias, and Dirk Czarnitzki 2001. The Effects of Public R\&D Subsidies on Firms' Innovation Activities: The Case of Eastern Germany. Journal of Business and Economic Statistics 21(2):226236.

Arrow, Kenneth. 1962. Economic Welfare and the Allocation of Resources for Invention. In The Rate and Direction of Inventive Activity: Economic and Social Factors, NBER, pp. 609-626. Princeton, NJ:

Princeton University Press.

Barbieri, Elisa, Marco R. Di Tommaso, and Lauretta Rubini. 2009. Industria Contemporanea: Governi, Imprese e Territori nella Cina Meridionale. Roma: Carocci Editore. 
Barbieri, Elisa, Roberto Iorio, and Giuseppe Lubrano Lavadera. 2010. Incentivi alla Ricerca e Sviluppo in Italia: una indagine sugli effetti della legge 46/82. L'Industria - Rivista di Economia e Politica Industriale 2:335-366.

Baron, Reuben M., and David A. Kenny. 1986. The Moderator-Mediator Variable Distinction in Social Psychological Research: Conceptual, Strategic, and Statistical Considerations. Journal of Personality and Social Psychology 5:1173-1182.

Bauer, Daniel J., and Patrick J. Curran. 2005. Probing Interactions in Fixed and Multilevel Regression: Inferential and Graphical Techniques. Multivariate Behavioral Research 40(3):373-400.

Borrás, Susana. 2003. The Innovation Policy of the European Union. From Government to Governance. Cheltenham, UK: Edward Elgar Publisher.

Borrás, Susana, and Charles Edquist. 2013. The Choice of Innovation Policy Instruments. Technological Forecasting and Social Change 80(8):1513-1522.

Carmichael, Jeffrey. 1981. The Effects of Mission-Oriented Public R\&D Spending on Private Industry. Journal of Finance 36:617-627.

Cerulli, Giovanni, and Bianca Potì. 2012. Evaluating the Robustness of the Effect of Public Subsidies on Firms' R\&D: An Application to Italy. Journal of Applied Economics 15(2):287-320.

Cohen, Wesley M., and Daniel A. Levinthal. 1989. Innovation and Learning: The Two Faces of R\&D. Economic Journal 99(397):569-596.

Cohen, Wesley M., and Daniel A. Levinthal. 1990. Absorptive Capacity: A New Perspective on Learning and Innovation. Administrative Science Quarterly 35(1):128-152.

Cohen, Wesly M., and Daniel A. Levinthal. 1994. Fortune Favors the Prepared Firm. Management Science 40(2):227-251.

Colombo, Massimo G., and Luca Grilli. 2007. Funding Gaps? Access to Bank Loans by High-Tech Start-ups. Small Business Economics 29:25-46.

Conte, Andrea, and Marco Vivarelli. 2005. One or Many Knowledge Production Functions? Mapping Innovative Activity Using Microdata. IZA Discussion Paper No. 1878, Bonn: IZA.

Czarnitzki, Dirk, and Katrin Hussinger. 2004. The Link Between R\&D Subsidies, R\&D Spending and Technological Performance. ZEW Discussion Papers, No. 04-56. Available at http://hdl.handle.net/10419/24065.

Czarnitzki, Dirk, and Cindy Lopes Bento. 2011. Innovation Subsidies: Does the Funding Source Matter for Innovation Intensity and Performance? Empirical Evidence from Germany. CEPS Working Papers No. 2011-42. Brussels: CEPS.

David, Paul A., and Bronwyn H. Hall. 2000. Heart of Darkness: Modeling Public-Private Funding Interactions Inside the R\&D Black Box. Research Policy 29(9):1165-1183.

Di Tommaso, Marco R., Elisa Barbieri, and Manli Huang. 2010. Industrial Development Policy and Innovation in Southern China: Government Targets and Firms Behaviour. European Planning Studies 18(1):83-105.

Di Tommaso, Marco R., and Lauretta Rubini. 2005. La geografia della produzione nel Guangdong: agglomerazioni di imprese e città specializzate. In La Sfida Industriale Cinese Vista dalla Toscana Distrettuale, edited by Marco Bellandi, and Mario Biggeri, pp. 39-78. Urbania: Stibu. 
Di Tommaso, Marco R., Lauretta Rubini, and Elisa Barbieri. 2012. Southern China. Industry, Development and Industrial Policy. Abingdon, UK: Routledge.

Di Tommaso, Marco R., and Stuart O. Schweitzer. 2013. Industrial Policy in America. Breaking the Taboo. Cheltenham, UK: Edward Elgar.

Dodgson, Mark, Alan Hughes, John Foster, and Stan Metcalfe. 2011. Systems Thinking, Market Failure, and the Development of Innovation Policy: The Case of Australia. Research Policy 140(9):11451156.

Edquist, Charles. 2001. Innovation Policy. A Systemic Approach. In The Globalizing Learning Economy: Major Socio-Economic Trends and European Innovation Policy, edited by D. Archibugi and B. A. Lundvall, pp. 219-238. Oxford: Oxford University Press.

Fu, Xiaolan, Jizhen Li, Hongru Xiong, and Henry Chesbrough. 2014. Open Innovation as a Response to Constraints and Risks: Evidence from China. Asian Economic Papers 13(3):30-58.

Geroski, Paul A. 1995. Innovation and Competitive Advantage. OECD Economics Department Working Paper No. 159. Paris: OECD.

Görg, Holger, and Eric Strobl. 2007. The Effect of R\&D Subsidies on Private R\&D. Economica 74(294):215-234.

Guan, Juan C., Chiu K. Mok, Richard C. M. Yam, K. S. Chin, and Kit F. Pun. 2006. Technology Transfer and innovation performance: Evidence from Chinese Firms. Technological Forecasting and Social Change 73(6):666-678.

Hall, Graham. 1991. Factors Associated with Relative Performance Amongst Small Firms in the British Instrumentation Sector. Working Paper No. 213. Manchester, UK: Manchester Business School.

Hansen, Gary S., and Birger Wernerfelt. 1989. Determinants of Firm Performance of Economic and Organizational Factors. Strategic Management Journal 10(5):399-411.

Harhoff, Dietmar. 2011. The Role of Patents and Licenses in Securing External Finance for Innovation. In Handbook of Research on Innovation and Entrepreneurship, edited by David B. Audretsch, Oliver Falck, Stephan Heblich, and Adam Lederer, pp. 55-73. Cheltenham: Edward Elgar Publisher.

Hayes, Andrew F. 2012. An Analytical Primer and Computational Tool for Observed Variable. Mediation, Moderation, and Conditional Process Modeling [White paper]. Available at www.afhayes.com/public/process2012.pdf.

Hayes, Andrew F., and Jörg Matthes. 2009. Computational Procedures for Probing Interactions in OLS and Logistic Regression: SPSS and SAS Implementations. Behavior Research Methods 41(3):924936.

Hosseini, Seyed M. P., and Suresh Narayanan. 2014. Adoption, Adaptive Innovation, and Creative Innovation Among SMES in Malaysian Manufacturing. Asian Economic Papers 13(2):32-58.

Jaccard, James, and Robert Turrisi. 2003. Interaction Effects in Multiple Regression, 2nd ed. Thousand Oak, CAs: Sage.

Kaiser, Ulrich. 2006. Private R\&D and Public R\&D Subsidies: Microeconomic Evidence from Denmark. Danish Journal of Economics 144(1):1-17.

Li, Xibao. 2012. Behind the Recent Surge of Chinese Patenting: An institutional view. Research Policy 41(1):236-249. 
Lichtenberg, Frank R. 1987. The Effect of Government Funding on private industrial Research and Development: A Re-Assessment. Journal of Industrial Economics 36(1):97-104.

Lu, Yi, and Zhigang Tao. 2009. Contract Enforcement and Family Control of Business: Evidence from China. Journal of Comparative Economics 37:597-609.

Lu, Yi, Zhigang Tao, and Yijiang Wang. 2010. Union Effects on Performance and Employment Relations: Evidence from China. China Economic Review 21:202-210.

Lööf, Hans, and Almas Hesmati. 2005. The Impact of Public Funding on Private R\&D Investment. New Evidence from a Firm Level Innovation Study. MTT Discussion Papers 3:1-26.

Mises, Ludwig von. Human Action. Auburn, AL: Ludwig von Mises Institute, 1949.

Oakey, Raymond P., Roy Rothwell, and Sarah Cooper. 1988. The Management of Innovation in High Technology Small Firms. London: Pinter.

OECD. 2008. OECD Reviews of Innovation Policy China. Technical Report. Paris: OECD.

Ortega-Argilés, Raquel, Mariacristina Piva, Lesley Potters, and Marco Vivarelli. 2010. Is Corporate R\&D Investment in High-Tech Sectors More Effective? Contemporary Economic Policy 28(3):353-365.

Ortega-Argilés, Raquel, Marco Vivarelli, and Peter Voigt. 2009. R\&D in SMEs: A Paradox? Small Business Economics 33(1):3-11.

Pantagakis, Emmanouil, Dimitrios Terzakis, and Stavros Arvanitis. 2012. R\&D Investments and Firm Performance: An Empirical Investigation of the High Technology Sector (Software and Hardware) in the E.U. Available at http://ssrn.com/abstract=2178919.

Petti, Claudio. 2012. Technological Entrepreneurship in China. How Does It Work? Cheltenham, UK, and Northampton, MA: Edward Elgar.

Petti, Claudio. 2014. Making R\&D Efforts Profitable: The Role of Absorptive Capacity and Policy Implications in an Emerging Economy Setting. Journal of Industrial and Business Economics 2/2014:6797.

Piekkola, Hannu. 2007. Public Funding of R\&D and Growth: Firm-level evidence from Finland. Economics of Innovation and New Technology 16(3):195-210.

Preacher, Kristopher J., Derek D. Rucker, and Andrew F. Hayes. 2007. Addressing Moderated Mediation Hypotheses: Theory, Methods and Prescriptions. Multivariate Behavioral Research 42(1):185227.

Rammer, Christian, Dirk Czarnitski, and Alfred Spielkamp. 2009. Innovation Process of Non-R\&D Performers: Substituting Technology by Management in SMEs. Small Business Economics 33(1):35-58.

Rubini, Lauretta, and Elisa Barbieri. 2013. Percorsi evolutivi nel sostegno alle imprese in Cina. Un'analisi delle imprese leader e riflessioni sulla politica industriale. L'Industria - Rivista di Economia e Politica Industriale 34(3):397-416.

Santarelli, Enrico, and Alessandro Sterlacchini. 1990. Innovation, Formal vs. Informal R\&D, and Firm Size: Some Evidence from Italian Manufacturing Firms. Small Business Economics 2:223-228.

Sher, Peter J., and Phil Y. Yang. 2005. The Effects of Innovative Capabilities and R\&D Clustering on Firm Performance: The Evidence of Taiwan's Semiconductor Industry. Technovation 25(1):33-43.

Sjöholm, Fredrik, and Nannan Lundin. 2010. Will Science and Technology Solve China's Unemployment Problem? Asian Economic Papers 9(2):1-28. 
Spithoven, André, Wim Vanhaverbeke, and Nadine Roijakkers. 2012. Open Innovation Practices in SMEs and Large Enterprises. Small Business Economics 41(3):537-562.

Stevens, James P. 1996. Applied Multivariate Statistics For The Social Sciences, ed. 3. Mahwah, NJ: Lawrence Erlbaum.

Stolzenberg, Ross M. 1980. The Measurement and Decomposition of Causal Effects in Nonlinear and Nonadditive Models. Sociological Methodology 11(1):459-488.

Tate, Richard L. 1998. Effect Decomposition in Interaction and nonlinear models. In Interaction and Nonlinear Effects in Structural Equation Modelling, edited by Randall E. Schumacker and George A. Marcoulides, pp. 167-181. Mahwah, NJ: Erlbaum.

Tidd, Joseph, and Michael Brocklehurst. 1999. Routes to Technological Learning and Development: An Assessment of Malaysia's Innovation Policy and Performance. Technological Forecasting and Social Change 62(3):239-257.

Toivanen, Otto, and Petri Niininen. 1998. Investment, R\&D, Subsidies and Credit Constraints. Working Paper. Cambridge, MA: MIT Department of Economics and Helsinki School of Economics.

Utterback, James M., and William J. Abernathy. 1975. A Dynamic Model of Process and Product Innovation. Omega 3(6):639-656.

Vivarelli, Marco. 2007. Entry and Post-Entry Performance of Newborn Firms. London and New York: Routledge.

Wakelin, Katharine. 2001. Productivity Growth and R\&D Expenditure in UK Manufacturing Firms. Research Policy 30:1079-1090.

Woolthuis, Rosalinde K., Bas Hillebrand, and Bart Nooteboom. 2005. Trust, Contract and Relationship Development. Organization Studies 26(6):813-840.

Xu, Erming, and Kai Xu. 2013. A Multilevel Analysis of the Effect of Taxation Incentives on Innovation Performance. IEEE Transactions on Engineering Management 60(1):137-147.

Zahra, Shaker A., and Gerard George. 2002. Absorptive Capacity. A Review, Reconceptualization and Extension. Academic Management Review 27(2):185-203.

Zhao, Changwen. 2010. No Simple Relationship Between Technological Improvements and Employment Generation in a Large Developing Country Like China: Thoughts Stimulated by Sjöholm and Lundin. Asian Economic Papers 9(2):35-43. 